\title{
EL MINERAL DE PAN DE AZÚCAR. ARQUEOLOGÍA HISTÓRICA DE UN CENTRO MINERO COLONIAL EN LA PUNA DE JUJUY (ARGENTINA)*
}

\author{
PAN DE AZÚCAR'S MINERAL. HISTORICAL ARCHAEOLOGY OF A COLONIAL \\ MINING CENTER IN THE JUJUY PUNA (ARGENTINA)
}

\author{
Carlos I. Angiorama ${ }^{1}$, María Florencia Becerra ${ }^{1}$ y María Josefina Pérez Pieroni ${ }^{1}$
}

\begin{abstract}
En este trabajo se presentan los resultados de una investigación sobre el asiento de mineral de Pan de Azúcar (sur de Pozuelos, Puna de Jujuy, Argentina), desarrollada en el marco de un proyecto más amplio sobre minería y metalurgia colonial en la región. Se detallan las menciones que sobre Pan de Azúcar hallamos en las fuentes escritas, las evidencias arqueológicas registradas en el campo, y los resultados de los análisis arqueométricos realizados sobre ellas. La explotación del yacimiento se habría iniciado a principios del siglo XVII y continuado de forma intermitente a lo largo de todo el período colonial, generando un poblado que no alcanzó la relevancia de otros centros mineros cercanos, pero que se destaca en el contexto del sur de Pozuelos en relación con la ocupación contemporánea, de carácter básicamente rural y sin acceso a bienes foráneos de raigambre europea.
\end{abstract}

Palabras claves: minería, período colonial, arqueometalurgia, arqueometría.

This paper presents the results of an ongoing research project at the mineral settlement of Pan de Azúcar (south of Pozuelos, Jujuy Puna, Argentina). This work is part of a wider research project on colonial mining and metallurgy in the region. Here, we detail the references to Pan de Azúcar found in the historic sources, the archaeological evidence recorded during fieldwork, and the results of the archaeometric analyses made on these recovered samples. The exploitation of the ore may have started in the early XVII century and continued intermittently during the whole colonial period. This gave rise to a settlement that, although not as important as other nearby mining centres, stood out in the context of the southern Pozuelos basin, compared to contemporary occupations, basically rural and without access to foreign goods of European origin.

Key words: Mining, Colonial Period, archaeometallurgy, archaeometry.

La presencia de riquezas minerales, especialmente de oro y plata, en la Puna de Jujuy, en los actuales departamentos de Yavi, Santa Catalina, Cochinoca y gran parte del de Rinconada (Jujuy, Argentina), generó en los colonizadores europeos un especial interés en estos territorios (Albeck y Palomeque 2009; Gil Montero 2004; Palomeque 2006; Sica y Ulloa 2007). Tanto mineros como comerciantes y trabajadores indígenas arribaron a la región en las primeras décadas del siglo XVII -también en momentos previos-, estimulando la creación de asientos de españoles y la instalación de campamentos mineros e ingenios (Gil Montero 2004; Sica 2006). Alrededor de 1660, el territorio puneño que concentraba las riquezas minerales se hallaba salpicado por una serie de asientos de mineral y pueblos localizados en las cercanías de las áreas mineras o vinculadas directamente a ellas (Becerra 2012). Aunque las expectativas generadas en torno a la explotación de los yacimientos de oro y plata de la región fueron muy grandes, esperando igualar o superar a los de áreas cercanas como las de Lípez o Chichas, o incluso al mismo Potosí, la minería puneña no logró equipararse a estos grandes centros mineros, y su economía regional dependió principalmente de las demandas de aquellos, a partir de las que se movilizó la producción de la Puna, principalmente ganadera, para el abastecimiento de los trabajadores (Conti 2010). Esta afirmación no niega, sin embargo, que la minería de oro y plata, aún a baja y mediana escala, jugó un papel muy relevante en la organización y dinámica del espacio y la población puneña durante el período colonial, como recientes investigaciones lo han demostrado

* Artículo seleccionado del conjunto de ponencias presentadas en el simposio Minería y metalurgia en los Andes, $54^{\circ}$ Congreso Internacional de Americanistas, Viena, Austria, 2012, simposio coordinado por Luis González y Diego Salazar. Editado por Diego Salazar y Valentina Figueroa, en su calidad de editores invitados de la Revista.

1 Instituto de Arqueología y Museo, Instituto Superior de Estudios Sociales (ISES-CONICET). San Martín 1545, San Miguel de Tucumán (4000), Argentina. carlosangiorama@gmail.com; florenciabecerra@gmail.com; josefinaperezp@gmail.com

Recibido: octubre 2013. Aceptado: octubre 2014.

http://dx.doi.org/10.4067/S0717-73562015005000045. Publicado en línea: 14-octubre-2015. 
(p.ej., Albeck y Palomeque 2009; Becerra 2009, 2014; Gil Montero 2004; Palomeque 2006; Sica 2006; Ulloa 2005). Se destaca la variedad de agentes en acción en torno a la actividad minera de la región. Por un lado, el análisis de la documentación colonial indica la participación de encomenderos, hacendados y empresarios que disponían de mano de obra, de recursos para invertir en las labores o de conexiones necesarias para encontrar personas que lo hicieran por ellos. Sin embargo, muchos de ellos no se dedicaron exclusivamente a la minería, siendo esta, salvo excepciones, o un emprendimiento relativamente fugaz, abandonado por problemas personales o intrínsecos a la actividad (inundaciones, agotamiento de la veta, entre otros) o complementaria a otras producciones de las haciendas (cf. Ulloa 2005). Por otro lado, también se observa una activa participación de los indígenas, locales o no, en dichos emprendimientos, ya fuera como mitayos, jornaleros o mineros independientes (Becerra 2014; Sica 2006).

Los emprendimientos mineros desarrollados en la región adquirieron diferentes características de acuerdo con el tipo de mineral y yacimiento, y por tanto, a los distintos requerimientos y recursos necesarios para su funcionamiento. En el caso de la explotación de minerales auríferos, no se distingue en la región puneña una gran inversión en infraestructura. Esto podría deberse, en parte, a la facilidad de acceso a los placeres y su laboreo. Las investigaciones arqueológicas han permitido registrar evidencias de extracción en piques y socavones en yacimientos en veta, y trincheras para el lavado de oro aluvial, instrumentos de molienda o marays, canales, plataformas empedradas y, en algunos casos, las viviendas de los trabajadores de dichas instalaciones, en las cercanías de las vetas o placeres. Asimismo, aún a esta baja escala, la minería del oro propició la fundación de poblados de gran relevancia regional, como las actuales cabeceras de los departamentos jujeños homónimos, San José de la Rinconada y Santa Catalina, u otros pueblos como Antiguyoc, Ajedrez, Santo Domingo u Oratorio (Angiorama y Becerra 2010, 2012). En el caso de las explotaciones de yacimientos argentíferos se han registrado instalaciones dedicadas al procesamiento de minerales ricos en plata de diversas escalas, desde un horno aislado hasta complejos de cuatro a cinco, probablemente funcionando en simultáneo, dedicados a la fundición y refinación de los minerales extraídos en yacimientos cercanos (Angiorama y Becerra
2010; Becerra et al. 2014), como Mina Chinchillas en Fundiciones y la importante mina de plomo, cinc y plata de Pan de Azúcar (Coira 1979).

En las inmediaciones de este último yacimiento, en el cerro homónimo, en el actual departamento de Rinconada (Jujuy, Argentina) (Figura 1), se localiza uno de los asientos de mineral fundados en torno a la actividad minera. Su explotación se habría iniciado en momentos coloniales y continuado intermitentemente hasta tiempos recientes. Por el momento no se cuenta con evidencias para postular una explotación anterior a la conquista europea, aunque sí hemos identificado allí ocupaciones prehispánicas. En este trabajo presentaremos los resultados del estudio conjunto de las evidencias arqueológicas registradas en este sitio, asignables a momentos coloniales, y de la documentación histórica y bibliográfica referente a él, con el objetivo de conocer las características que adquirió dicho asiento, especialmente aquellas vinculadas a las actividades minero-metalúrgicas desarrolladas allí, pero también a otras prácticas cotidianas de los habitantes y trabajadores del yacimiento durante la colonia. Consideramos que el análisis en profundidad del asiento de Pan de Azúcar y sus pobladores resulta una contribución para el conocimiento de la dinámica del desarrollo minero en la Puna y de quienes llevaron adelante esta actividad en la región.

\section{El Mineral del Pan de Azúcar en la Documentación Histórica}

La documentación colonial referida a los asientos de mineral y emprendimientos mineros de la Puna de Jujuy no es abundante ni elocuente en las descripciones. La misma se encuentra en diversos archivos nacionales y provinciales como el Archivo y Biblioteca Nacional de Bolivia (ABNB), Sucre, el Archivo General de la Nación (AGN), Buenos Aires, el Archivo Histórico Provincial de Jujuy (AHPJ), el Archivo de Tribunales de Jujuy (ATJ) y el Archivo y Biblioteca Históricos de Salta (ABHS). A partir del análisis crítico de dicha documentación y de los estudios previos que sobre los mismos se habían realizado, contamos con datos dispersos que, junto con los resultados de la investigación arqueológica, nos permiten ir armando un primer panorama acerca del funcionamiento y características de estos asientos y campamentos que concentraron a la población minera del área puneña. En este apartado haremos una breve revisión de lo que 


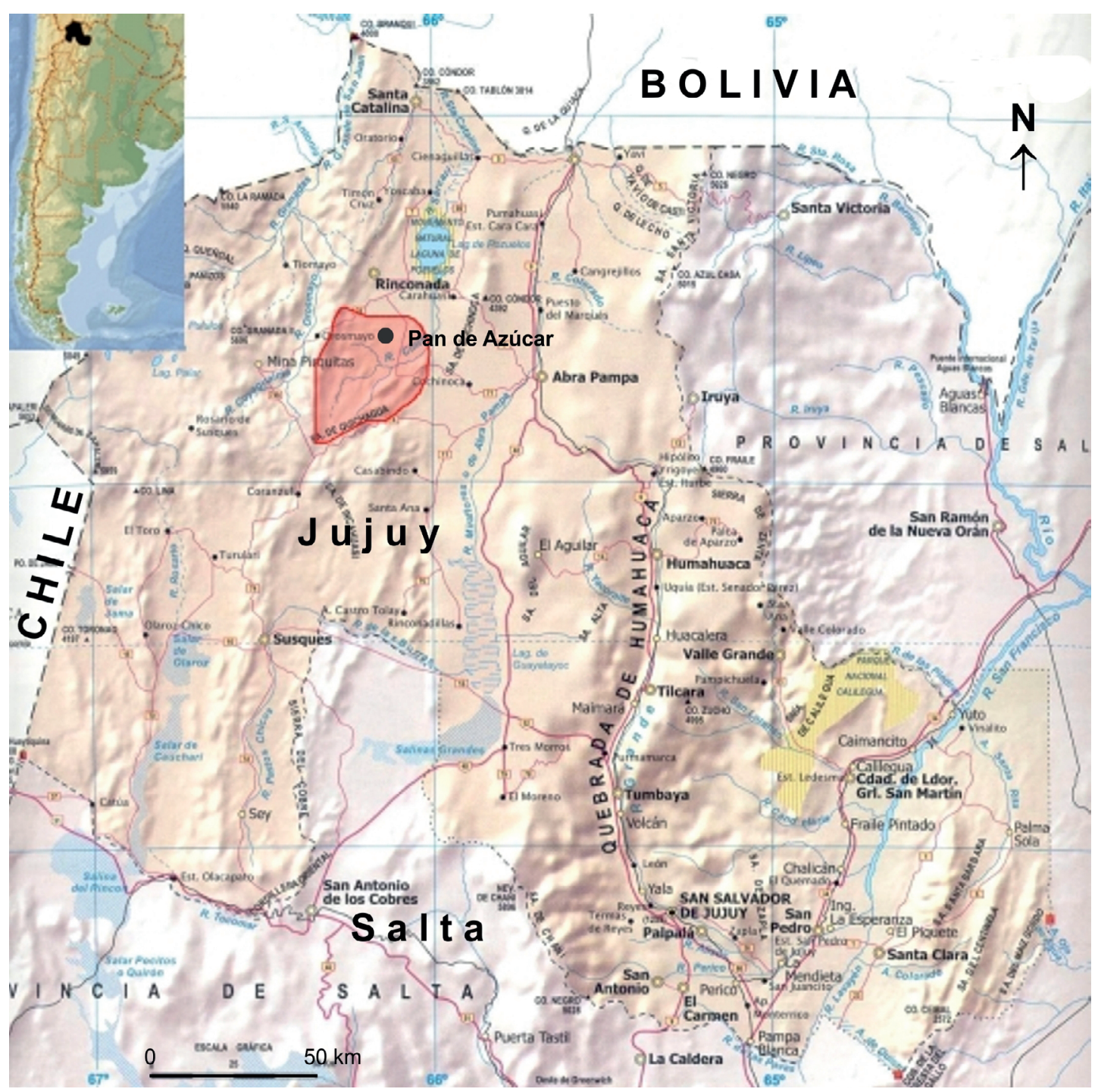

Figura 1. Mapa de ubicación de Pan de Azúcar. El área sombreada indica el sur de la cuenca de Pozuelos, nuestra área de estudio. Map showing the location of Pan de Azúcar. The shaded area indicates the southern Pozuelos basin, our study area.

conocemos sobre el mineral de Pan de Azúcar por medio de la documentación colonial.

Analizando el proceso de ocupación europea del espacio puneño y del desarrollo de la actividad minera colonial, observamos que en la primera mitad del siglo XVII las explotaciones se habrían concentrado en las cercanías del pueblo de reducción de indios de Cochinoca, en un yacimiento de plata referido en la documentación como Cerro Espíritu Santo. También habrían sido relevantes las explotaciones auríferas localizadas en las inmediaciones de Santiago de la Rinconada del Oro, asiento de mineral. Como señalaron Sica (2006:193-194) y
Albeck y Palomeque (2009:186), no es casual que sea en el área del centro de la puna, al sur de la laguna Pozuelos, donde se concentraron a su vez las primeras mercedes de tierra concedidas entre los años 1594 y 1636.

Revisando la bibliografía geológica sobre la historia de las explotaciones en el área, encontramos que la mina de Pan de Azúcar era conocida "desde el tiempo de los jesuitas". "Su mineral era rosicler y sus desmontes, según cuenta la crónica, produjeron ingentes marcos de plata a sus tenedores, beneficiándose por fundición" (Catalano 2004:131, 28). "Los trabajos mineros fueron realizados por 
la comunidad jesuita de donde deriva el nombre homónimo con que luego se identificara a la veta que afloraba en el criadero [la veta jesuita]" (Segal y Caffe 1999:1581). Sin embargo, no hay evidencias concretas de que alguna de las explotaciones mineras puneñas haya sido llevada a cabo por la Compañía de Jesús (cf. Gil Montero 2009), sino más bien por mineros particulares tanto europeos como indígenas. La documentación de la época muestra los emprendimientos de varios encomenderos en el área, quienes invertían capitales, aportaban la mano de obra indígena de sus encomiendas y se asentaban en la región, incluso con sus familias (cf. entre otros Palomeque 2006; Sica y Ulloa 2007). Por otra parte, también se sabe del establecimiento de compañías entre mineros españoles, beneficiados con mercedes de tierras en el área o no. En cuanto a los mineros indígenas, estos explotaban minas de forma independiente o a jornal de mineros europeos.

Documentación de inicios del siglo XVII se refiere a los minerales de Cochinoca, diciendo que "prometen mucha riqueza y se van poblando de españoles que acuden a poblarlas y trabajar en ellas" (1601, La Plata, CGGV, n 3346 en Palomeque 2006:27). Por otra parte, se sabe de la instalación de un ingenio en las primeras décadas del siglo XVII, para el procesamiento de los minerales de plata extraídos en el área. En los "términos del pueblo de indios de Cochinoca y Cerro Rico" se construyó un "ingenio de moler metales ricos de plata con todas las caserías, edificios y corrales y tierras", llamado San Joseph de Cochinoca (ABHS, Colección Marquesado Valle de Tojo -CMVT-, Escribanías públicas, Año 1737, f. 35). Éste habría procesado los minerales extraídos en el Cerro del Espíritu Santo de Cochinoca (ATJ, Carpeta 5, Leg. 86, f. 1). Desafortunadamente, las investigaciones arqueológicas desarrolladas en el área no han permitido aún la localización de dicho ingenio, abandonado ya en 1662 .

Considerando la propuesta de Albeck y Palomeque (2009:190) de que el emplazamiento prehispánico principal de los cochinocas, llamado Pucará de Cochinoca en la documentación, sería el Pucará de Rinconada, se observa que en la fisiografía del sector donde se ubica este sitio se destaca la presencia del cerro Pan de Azúcar. A primera vista resultaría adecuado suponer que el cerro y mina Pan de Azúcar se corresponde con el yacimiento del cerro Espíritu Santo de Cochinoca mencionado en la documentación temprana. Sin embargo, la documentación no es tan clara al respecto. Por un lado, aunque la referencia a un cerro como Pan de Azúcar la encontramos en documentación fechada en el año 1627 (ABHS, CMVT, Año 1737), aún en 1646 se continúa hablando del asiento de minas de plata de Cochinoca, sin hacer ninguna mención al epíteto Pan de Azúcar (ABNB, Minas 62-3, Año 1646 , f. 1), lo cual nos hizo pensar que no se estaban refiriendo al mismo yacimiento. Esto, sumado a que habíamos encontrado una referencia a él como "un cerro que llaman del Pan de Azúcar, mineral de plata" (ATJ, Carpeta 26, Leg. 794, Año 1706, f. 1) recién a inicios del siglo XVIII, nos sugería que la explotación minera allí habría comenzado en ese siglo y no en las primeras incursiones europeas al territorio. Por el contrario, nueva documentación consultada en el Archivo General de la Nación (AGN) nos regresó a la primera hipótesis. En un expediente, iniciado por el marqués del Valle de Tojo, encomendero de la región, este denunciaba que en 1683 "se juntaron en el Pan de Azúcar con pretexto de minas más de veinte hombres facinerosos", quienes llegaban al pueblo de Cochinoca "a sacar indios para la labor de minas del Pan de Azúcar", alegando ser primeros descubridores del yacimiento. Esto, de acuerdo con el marqués, era ilegal, ya que el "cerro del Pan de Azúcar es mineral trabajado y tan antiguo que pasa de setenta años", con "ingenio y trapiches que se despoblaron como parece de las ruinas que de ellos se ve" (AGN, Sala XIII, Documentos Diversos, Sección Colonial, Leg. 11, f. 208 y 175-175v). A partir de este alegato se puede aventurar que el ingenio y trapiche de Cochinoca, mencionado más atrás, podría ser aquel abandonado setenta años después en Pan de Azúcar, o al menos, que este yacimiento tuvo una explotación temprana y una reanudación de labores a finales del siglo XVII para la cual veinte hombres se encontraban interesados en conseguir mano de obra de los indios encomendados de la región.

Nada más se sabe, hasta el momento, de la suerte de esa explotación, sólo que en el año 1761 Alonso de Celis solicita allí una veta "de fundición" (Rodríguez 1916:348). Un año después, hallamos un pedido para "instalar hornos y fundir", firmado en la localidad de San Miguel de Pan de Azúcar (ABHS, CMVT, Año 1737, Expedientes varios, f. 28v). Aunque no hay referencia al lugar en el que estos hornos irían a construirse y, por lo tanto, de qué mina se extraería el mineral, puede pensarse que sería en dicha localidad. Además indica que "todos estos años han estado varios indios, fundiendo a su libertad en los rincones de las tierras pertenecientes a esa ilustre casa de Yavi por la comodidad de la 
leña" (ABHS, CMVT, Año 1737, Expedientes varios, f. 28v).

Años más tarde, en 1789, un importante comerciante y hacendado, Ángel Antonio de la Bárcena, formó junto a Manuel Fernández de Baldivieso una compañía para trabajar esa mina de plata y la del cerro de San Pedro de Agua Caliente en la Jurisdicción de Atacama (Ulloa 2005; Becerra 2009, 2012). Las explotaciones se habrían vinculado con el trabajo en la hacienda de Bárcena, quien poseía una cancha para hacer matanzas de ganado "a fin de mantener el continuo trabajo de minas" (ATJ, Carpeta 59, Leg. 1915, Año 1789, f.16; Gil Montero 2004:42).

Para 1799, según el informe de Rafael de la Luz, el yacimiento de Pan de Azúcar habría estado abandonado, ya que no había en la región suficientes personas para el laboreo de las minas y tenía "además contra si la mucha agua que es difícil extraer por máquinas y no hay como darles socavón" (AGN, Tribunales 36-2-5, f. 11 y 11v; Acevedo 1965; Ulloa 2005).

\section{Investigaciones Arqueológicas en Pan de Azúcar}

El pueblo actual de Pan de Azúcar se ubica sobre la falda norte del cerro homónimo, y consiste básicamente en unas pocas viviendas con ocupación permanente (no más de tres), una capilla, un salón comunal y una escuela que nuclea la población infantil de los alrededores. A unos 2,5 km hacia el sudeste, en la falda occidental de una serie de elevaciones de menor altura, se localizan las ruinas de la mina Pan de Azúcar, en explotación hasta fines de la década de 1970 (Figura 2). Allí perduran hoy maquinarias, barracas, una capilla y una escuela, pero tan solo vive de forma permanente el cuidador de la mina y su familia. En los alrededores de las elevaciones mencionadas existen algunos puestos actuales de ocupación temporaria, a diferencia de lo que ocurre en el cerro Pan de Azúcar, donde la población se concentra únicamente en el poblado.

A partir de 2004 iniciamos en este sector de la cuenca de Pozuelos prospecciones intensivas, de cobertura total, que nos permitieron registrar las evidencias arqueológicas presentes tanto en el cerro Pan de Azúcar como en las elevaciones cercanas. Relevamos las estructuras detectadas, tomamos muestras de los materiales superficiales, y registramos las fuentes de recursos naturales disponibles (minerales metalíferos, materias primas líticas, agua, entre otros). Luego excavamos una estructura habitacional completa, y sondeamos otros espacios domésticos, estructuras agrícolas y una cueva. Los trabajos realizados dieron lugar al hallazgo de evidencias de una ocupación de larga data. Varias puntas de proyectil halladas en superficie se remontan al período Arcaico (Angiorama et al. 2013). Algunos recintos asociados con estructuras agrícolas y corrales han sido ocupados durante el siglo XV de acuerdo con los fechados radiocarbónicos

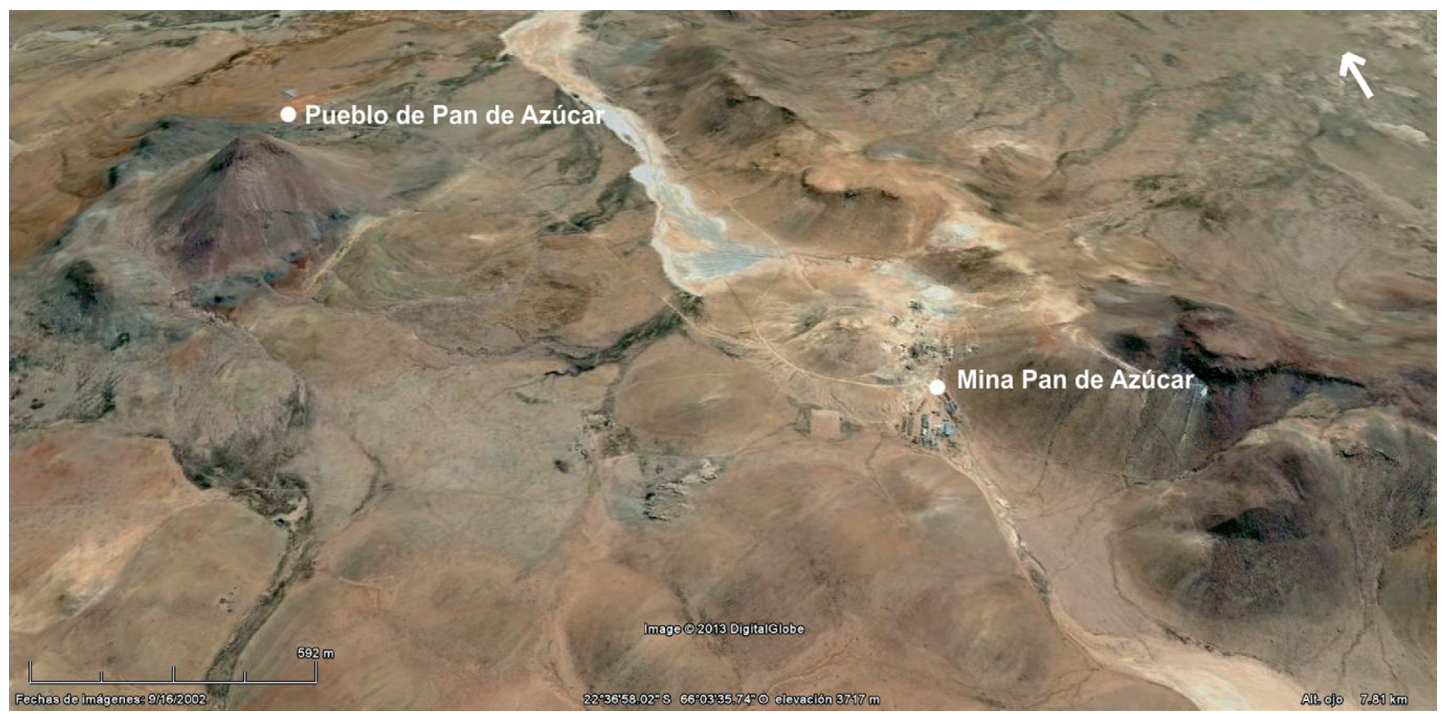

Figura 2. Vista aérea del pueblo de Pan de Azúcar y la mina Pan de Azúcar. Aerial view of the Pan de Azúcar village and Pan de Azúcar mine. 
obtenidos, época en la que probablemente tuvieron lugar las ofrendas de mineral en la cima de los cerros prospectados (Angiorama 2011). Varias de las estructuras registradas no excavadas, sin embargo, pudieron haber sido ocupadas tanto en época prehispánica tardía como colonial, ya que la arquitectura local de tiempos coloniales en muchos casos no muestra diferencias significativas apreciables desde superficie respecto de la arquitectura prehispánica (Angiorama y Pérez Pieroni 2013).

Entre las evidencias arqueológicas que podemos asignar con seguridad a época colonial se encuentran los restos de una pequeña capilla localizada en las cercanías del pueblo actual de Pan de Azúcar, de la cual no tenemos aún datos sobre su fecha de construcción y de abandono. A unos $200 \mathrm{~m}$ de ella, el escurrimiento de agua ha dejado al descubierto un estrato de unos $40 \mathrm{~cm}$ de potencia y una gran extensión compuesto por una acumulación de restos óseos de fauna autóctona (camélidos) y europea (al menos cabras), que podrían llegar a corresponder, quizás, a los desechos del matadero que organizó Bárcena en la última década del siglo XVIII para el mantenimiento de los trabajadores de la mina, si es que este fue construido en Pan de Azúcar.

En el mismo sector, a unos $150 \mathrm{~m}$ al este de la capilla, hemos registrado un área de unos $20 \mathrm{~m}$ de diámetro donde se observa una gran cantidad de escoria metalúrgica tapizando la superficie (sitio Pan de Azúcar 1, PA1). Los habitantes del actual pueblo de Pan de Azúcar denominan al lugar como el "escorial". En este sector se registraron dos bases de hornos delimitados por rocas rojizas termoalteradas. Una de las bases parecería haber conformado parte de la entrada lateral del horno, mientras que la segunda es menos definida y forma únicamente un ángulo recto. En la ladera opuesta del cerro Pan de Azúcar, la sur, hemos registrado un horno parcialmente conservado, sin otras estructuras asociadas a él (sitio Pan de Azúcar 26, PA26) (Figura 3). Presenta una bóveda de $2 \mathrm{~m}$ de diámetro, cuyos muros están en parte derrumbados y se observan evidencias de la presencia de una posible caja de fuego y de una chimenea conectada por un conducto superficial, también parcialmente destruido. Con una abertura circular superior y una lateral sellada, además de las que comunicarían la bóveda con las otras partes del horno. No se observan orificios de ventilación. Por sus características podemos señalar que se trata de un horno de tipo reverbero, similar a otros que hemos registrado en la región, en donde el combustible no habría entrado en contacto con la carga de mineral a fundir (Angiorama y Becerra 2010; Becerra et al. 2014). En asociación con el horno se recuperaron 13 fragmentos de sedimento consolidado cubierto por una superficie vitrificada, conocidas en la literatura especializada como escorias de combustión (cf. González 2004), 30 desechos de fundición, es decir, mezclas formadas durante la fundición de la ganga y fundentes, y 11 fragmentos de cerámica sin tratamiento de superficie. Ninguna de las evidencias presentes en el sitio nos permite fechar la construcción y empleo del horno con certeza. Complica aún más la asignación cronológica el hecho de que, como vimos, en distintos momentos de la colonia y luego también en época republicana, se asentaron mineros deseosos de explotar el yacimiento homónimo, a diferentes escalas y con diversos recursos. Sin embargo, su similitud con las tecnologías empleadas en las instalaciones metalúrgicas de la región andina en momentos coloniales (cf. Alonso Barba 1939 [1640]) y la ausencia de registros escritos u orales de la construcción de este horno en tiempos más recientes, nos lleva a establecer tentativamente su cronología en el período colonial.

Volviendo a la ladera norte del cerro Pan de Azúcar, a unos $250 \mathrm{~m}$ al oeste de la capilla en ruinas, hemos localizado un basurero (sitio Pan de Azúcar 22, PA22) que consiste en una acumulación de material arqueológico que configura una pequeña lomada parcialmente erosionada por un curso de agua temporario. No se encuentra asociado directamente a alguna estructura en particular, pero se emplaza en un sector en el que existen algunas construcciones (recintos y corrales) cuya antigüedad aún no hemos podido establecer, y donde abundan en superficie

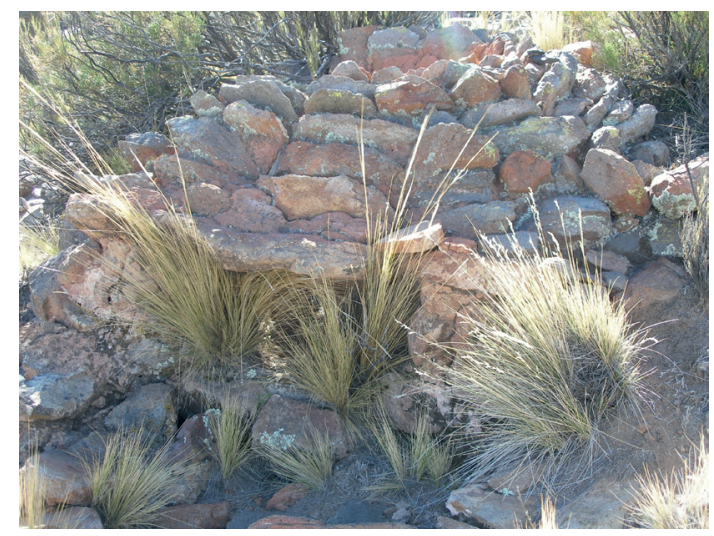

Figura 3. Horno metalúrgico de Pan de Azúcar 26. Metallurgical furnace in Pan de Azúcar 26. 
las evidencias de ocupación prehispánica y, sobre todo, colonial.

Excavamos en el basurero un sondeo de 50 $\mathrm{cm}$ de lado. El estrato que contiene los materiales arqueológicos presenta una potencia de unos 30 $\mathrm{cm}$, sin niveles estratigráficos diferenciables. La limpieza de parte del perfil originado por el curso de agua permitió constatar lo observado en el sondeo y estimar que el basurero se extiende por un área de al menos unos catorce metros de diámetro. Mediante la excavación se recuperaron fragmentos cerámicos, huesos de fauna, material lítico tallado, un topu metálico, escoria metalúrgica y carbón. Se efectuó un fechado por ${ }^{14} \mathrm{C}$ a partir de una muestra de carbón tomada del techo del nivel con material arqueológico. El resultado se muestra en la Tabla 1. El área relativa bajo la curva de calibración indica que existe una probabilidad de 0,82 de que el fechado corresponda al lapso comprendido entre 1640 y 1810 d.C.

También se encontró escoria en superficie, tanto de fundición como de combustión, en diversos sectores de la ladera norte del cerro Pan de Azúcar, además de los contextos mencionados (PA1 y PA22). Es un tipo de material abundante en el lugar, que ha sido recolectado repetidamente en época reciente a fin de aprovechar el metal entrampado. Si bien se trata de escoria muy probablemente generada durante época colonial, su traslado de un lugar a otro ha ampliado su distribución superficial, por lo que su sola presencia en determinados sectores no constituye un indicador de la antigüedad del contexto de hallazgo. Las únicas excepciones las constituyen PA1 (donde se observan las bases de los hornos metalúrgicos), PA26 (donde se conserva gran parte del horno en el que fueron generadas), y PA22 (fechado por radiocarbono).

\section{Estudio de las Evidencias Coloniales}

\section{Residuos metalúrgicos}

En distintos sectores del Pan de Azúcar se han registrado residuos de actividad metalúrgica. El análisis de este tipo de evidencias nos permite acercarnos, a partir de la composición química de su matriz y de las formaciones cristalinas atrapadas en ellos, al mineral de aporte (mena) usado en la fundición -primer paso de la cadena metalúrgica-, proporcionándonos información sobre las técnicas empleadas y las decisiones tecnológicas vinculadas al tipo de metal producido (Cohen et al. 2008).
Tabla 1. Fechado ${ }^{14} \mathrm{C}$ de PA 22, McCormac et al. 2004. Calibration data set: shcal04.14c, McCormac et al. 2004.

\begin{tabular}{cccc}
\hline Código & Edad ${ }^{14} \mathrm{C}$ & $\begin{array}{c}\text { Cal. d.C. } \\
1 \text { sigma }\end{array}$ & $\begin{array}{c}\text { Area relativa } \\
\text { bajo la curva }\end{array}$ \\
\hline LP- 2105 & $230 \pm 70$ a.p. & $1640-1706$ & 0,32 \\
& & $1721-1810$ & 0,50 \\
& & $1837-1846$ & 0,03 \\
& & $1858-1861$ & 0,01 \\
& & $1866-1879$ & 0,04 \\
& & $1925-1950$ & 0,09 \\
\hline
\end{tabular}

De aquellas escorias recuperadas en contexto (Pan de Azúcar 1, 22 y 26) se seleccionaron algunas muestras para ser analizadas por microscopio metalográfico de reflexión y posteriormente, algunas de ellas, con microscopio electrónico de barrido (SEM), a fin de conocer la naturaleza de la carga mineral y las condiciones de los procesos metalúrgicos desarrollados. Para ello se tomaron imágenes digitales con sensores de electrones secundarios y retrodifundidos, que permitieron identificar fases de distinta composición química a las que se les realizó análisis cualitativo por espectroscopia de energía dispersiva de rayos $\mathrm{X}$ (EDE) y en algunos casos, cuantitativo. La interpretación de los datos se realizó fase por fase identificada en cada muestra. En el caso de dos de las muestras, provenientes de PA 22, se analizó su composición mediante Microsonda Electrónica de Barrido (WDS) ${ }^{1}$.

Los residuos metalúrgicos analizados son de tres tipos: escorias de fundición, escorias de combustión y desechos metálicos. En cuanto a los asignables a la primera clase, dos provenientes de Pan de Azúcar 26 y asociadas al horno de reverbero allí presente fueron analizadas en profundidad. Consisten en una matriz vítrea predominante, compuesta por aproximadamente un $30 \%$ w de $\mathrm{SiO}_{2}$ y $35 \%$ w de $\mathrm{PbO}$, y principalmente por óxidos de calcio, magnesio y aluminio, como también por flúor, cloro, cobalto, molibdeno e indio (este último presente solo en una de las escorias), en porcentajes en peso menores. También se detectó Ag en bajísima proporción $(0,04$ a $0,56 \%$ w). Ambas escorias presentan inclusiones no metálicas, de forma hexagonal y lineal, que consisten mayormente en $\mathrm{P}_{2} \mathrm{O}_{5}$ y CaO, aunque se detectó $\mathrm{PbO}$ en bajo porcentaje y aún en menor medida Ag. El azufre se presenta también en bajas proporciones (no alcanza el 2,5\% w en análisis puntuales). En una de las muestras solo se 
detectó una medición, con 1,62\% w en una figura hexagonal, y en la otra no alcanza el 2,5\% w (y se concentra principalmente en las inclusiones). La muestra estudiada proveniente de PA1 dio similares resultados, aunque solo se realizaron mediciones cualitativas mediante SEM-EDS. La matriz de la misma arrojó una composición de $\mathrm{Pb}, \mathrm{O}, \mathrm{Si}, \mathrm{Al}, \mathrm{P}$, $\mathrm{Fe} \mathrm{y} \mathrm{Ag.} \mathrm{En} \mathrm{esta} \mathrm{se} \mathrm{encontraban} \mathrm{círculos} \mathrm{que} \mathrm{en}$ microscopio óptico tenían un aspecto de mal pulido y dos fases en su interior (una oscura y otra brillante). Los análisis mostraron que consistían mayormente en $\mathrm{Pb}, \mathrm{Ag}$ y $\mathrm{O}$, concentrándose la $\mathrm{Ag}$ en ciertos puntos. No pudimos distinguir si los círculos y la matriz consisten solo en $\mathrm{Pb}$ o si el $\mathrm{S}$ está también presente y en qué proporción debido a las limitaciones de la técnica. De PA22 se analizó una escoria de este tipo en microscopio óptico y dos más recuperadas en una de las estructuras cercanas al basurero, pero cuya vinculación y asignación cronológica no está clara aún. Todas ellas presentan una matriz vítrea homogénea, con presencia de círculos de aspecto mal pulido e inclusiones doradas pequeñas, circulares, dispersas en la matriz o vinculadas con los círculos rugosos. También se observan, especialmente en una de las muestras de la estructura, inclusiones opacas grises (Figura 4). Aunque no contamos con análisis de composición de estas muestras, podemos afirmar que tienen casi idénticas características a las halladas asociadas al horno de PA26 y a la analizada en PA1, y por tanto parecerían ser el producto de procesos similares.

Del segundo tipo, las escorias de combustión, se analizaron tres muestras provenientes de PA26. Su descripción resulta mucho más compleja, ya que las mismas, por definición, se componen de sedimentos que han sido termoalterados y han generado un esmalte vitrificado que está formado por los elementos presentes en el sedimento y, a su vez, por los de los minerales fundidos con los que estuvieron en contacto. En nuestro caso, en el esmalte de estas muestras se detectaron, como en las matrices de las escorias de fundición, principalmente $\mathrm{SiO}_{2}$ (31\% w en promedio) y $\mathrm{PbO}(33,5 \% \mathrm{w})$, con presencia de $\mathrm{Ag}$ en dos de ellas $(0,3 \% \mathrm{w})$, además de óxidos de aluminio y calcio, entre otros. En este esmalte, como en el interior poroso del sedimento termoalterado, se observaron inclusiones. En un solo caso, en este último sector de una de las muestras, una inclusión consistía en casi exclusivamente $\mathrm{Fe}_{2} \mathrm{O}_{3}$. El resto eran, mayormente, aluminosilicatos con una proporción promedio de $19 \% \mathrm{w} \mathrm{de}_{2} \mathrm{Al}_{2} \mathrm{O}_{3} \mathrm{y}$

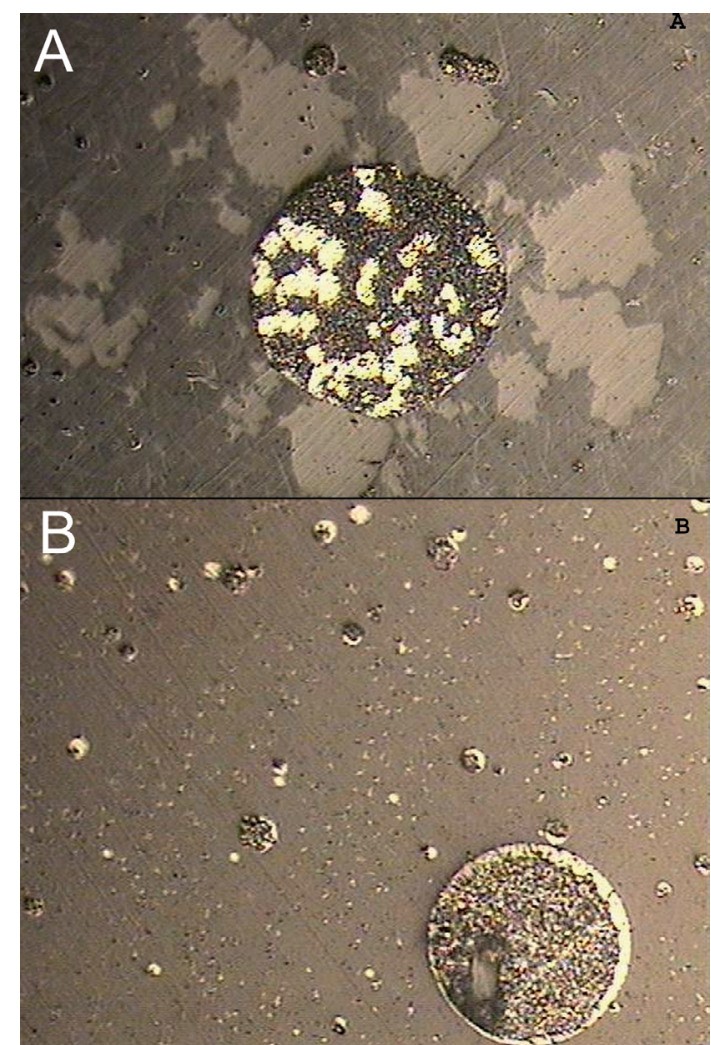

Figura 4. Micrografías de escorias vítreas donde se observa la matriz con inclusiones metálicas. Imagen tomada con microscopio óptico a aumento de 125x. Referencias: A: muestra de PA1. B: muestra del basurero de PA 22.

Vitrified slags microphotographies, where the mould shows metallic inclusions. Pictures taken with optical microscope at 125x magnification. References: A: sample from PA1. B: sample from PA22 discard area.

$55 \%$ w de $\mathrm{SiO}_{2}$. En cuanto a la presencia de $\mathrm{Ag}$ en estas inclusiones, cuando se detectó, los porcentajes variaron desde 0,02 a $0,33 \%$ w y en una sola medida aislada $21,5 \%$ w. No logramos repetir este resultado por lo que no pudimos detectar una fase o inclusión en que se concentrara este elemento en esa proporción. Para el caso del azufre, se midió en un $1,8 \%$ w en una fase rectangular, pero sus valores en las tres muestras variaron de 0,01 a $0,3 \%$ w en la mayoría de las mediciones.

Solo dos muestras provenientes de PA22 y de una estructura cercana, tienen aspecto metálico, lo que las diferenciaba de las típicas escorias de fundición vítreas predominantes, por lo que fueron analizadas con mayor detenimiento. La muestra recuperada en el basurero excavado consiste en un fragmento de aspecto metálico de 2,8 $\mathrm{g}$ de peso y de 
aproximadamente $3 \mathrm{~cm}$ de largo. En microscopio metalográfico se observa que la superficie de esta muestra presenta una fase brillante de figuras rectangulares o hexagonales, una matriz de aspecto rugoso y una tercera fase, más homogénea y oscura. Fue analizada primero mediante EDS y luego por WDS. Estos análisis nos indicaron que esta fase brillante o clara consiste en $\mathrm{Pb}$ y S en 50\% at cada uno, es decir, similar a la composición de la galena (sulfuro de plomo que está presente en el yacimiento de Pan de Azúcar). Alrededor de estas inclusiones se observa un perímetro que está compuesto por $\mathrm{Ag}$ y $\mathrm{S}$ (probablemente argentita o pirargirita, también presente en la mina). La matriz se compone de óxido de plomo ( $\mathrm{PbO}$-litargirio-). La fase más oscura, de forma rectangular consiste principalmente en $\mathrm{Pb}, \mathrm{Si}$ y Al. En síntesis, esta muestra presenta una matriz de óxido de plomo con algunas inclusiones de sulfuro de plomo rodeada por sulfuro de plata. Inclusiones de silicatos, aluminosilicatos o silicatos de plomo también se encuentran presentes. Esta composición es la esperable siendo que el yacimiento cercano es de $\mathrm{Pb}, \mathrm{Ag}$ y $\mathrm{Zn}$. De todos modos, se hace necesaria una investigación más profunda sobre las características de la mena para entender mejor esta muestra.

La muestra recuperada en la estructura cercana al basurero es muy similar a la anterior aunque su tamaño es mucho más reducido. Se encontró en excavación, en un nivel de relleno del recinto, donde se concentraba la mayor parte del material allí recuperado. Es la única muestra de aspecto metálico de las 95 halladas mediante excavación. La matriz es similar a la de la muestra del basurero, pero hay ciertas inclusiones que merecieron nuestra atención. En el borde de la muestra se observó una fase oscura, compuesta mayormente de $\mathrm{Si}, \mathrm{O}$ y Al. También se observan dos fases brillantes, de formas diferentes: algunas de figuras circulares y otras de forma dendrítica. Esta fase se compone mayormente de sulfuro de plomo (entre 20 y $40 \%$ at cada uno). $\mathrm{Cu}, \mathrm{Ag}, \mathrm{Sb}$ y $\mathrm{O}$ también están presentes en bajos porcentajes. Las figuras dendríticas presentan $\mathrm{Ag}$ (de 11 a $40 \%$ at), $\mathrm{Pb}$ (20 a 36\% at), $\mathrm{Sb}$ (2 a 5\% at), $\mathrm{O}(22$ a $47 \%$ at) y $\mathrm{Cu}(2,8 \%$ at máximo) (Figura 5$)$.

Se detectó una quinta fase en algunas de las figuras redondeadas: fase eutéctica bicolor (oscura y brillante) que consiste en $\mathrm{S}$ ( 20 a $30 \%$ at), $\mathrm{Pb}$ (26 a $38 \%$ at) y O (15 a $26 \%$ at). También se detectó un alto porcentaje de $\mathrm{Cu}$ ( 8 a $20 \%$ at), y en bajas proporciones, Ag y Sb. A primera vista esta muestra parece muy similar a la anterior, pero la presencia de figuras dendríticas de $\mathrm{Ag}-\mathrm{Pb}-\mathrm{O}$ o la detección de $\mathrm{Cu}$ y $\mathrm{Sb}$, para dar algunos ejemplos, le brindan algunas particularidades. El tamaño de la muestra y la ausencia de otras similares hacen difícil llegar a una conclusión.

La interpretación de los resultados obtenidos, aunque preliminares, indica que en los sitios coloniales de Pan de Azúcar se realizaba la primera fundición de minerales de plomo con contenido de plata, de acuerdo con la cantidad de silicato de plomo que conforma la matriz de las escorias y el esmalte de los sedimentos vitrificados analizados. Esto permitiría postular el beneficio de los minerales presentes en el yacimiento homónimo, cercano al sitio. El bajo porcentaje de plata en las escorias, así como la ausencia de grandes inclusiones metálicas de este mineral, indica que el proceso de su beneficio por fundición fue considerablemente eficiente, ya que este no se habría perdido en la matriz, sino que se habría combinado con el plomo metálico. Esta aleación debería ser refinada posteriormente. Otro dato que lleva a pensar en condiciones de oxidación y altas temperaturas que permitan el buen desarrollo del proceso, es la escasa presencia de azufre en las muestras analizadas por SEM/EDS, elemento que solo se presenta en escorias cuando no puede liberarse a la atmósfera como dióxido de azufre debido a que estas condiciones no son las adecuadas.

Una cuestión importante para responder, con relación a las escorias metálicas analizadas, es la ubicación de estas en los diferentes pasos de la cadena minero-metalúrgica. Los principales problemas que enfrentamos a la hora de resolver esta problemática son los contextos de hallazgo y el hecho de que son únicamente dos muestras. Sin embargo, los análisis nos han habilitado a delinear algunas cuestiones, que, por supuesto, deben ser confirmadas con nuevos trabajos de campo, análisis de muestras y experimentación. Hasta el momento, se puede señalar que la presencia de sulfuro de plomo y plata, y la ausencia de aleaciones de plata-plomo en la muestra (como las observadas en el otro tipo de muestras) nos refieren a las primeras etapas de la cadena. Si se analizan las reacciones químicas envueltas en el proceso, vemos que durante el tostado de los sulfuros de plomo y plata, el sulfuro de plomo sufre su primera transformación de sulfuro a óxido y sulfato $\left(3 \mathrm{PbS}+5 \mathrm{O}_{2}=2 \mathrm{SO}_{2}+\mathrm{PbO}+\mathrm{PbSO}_{4}\right)$, en una reacción incompleta, porque no todo el 


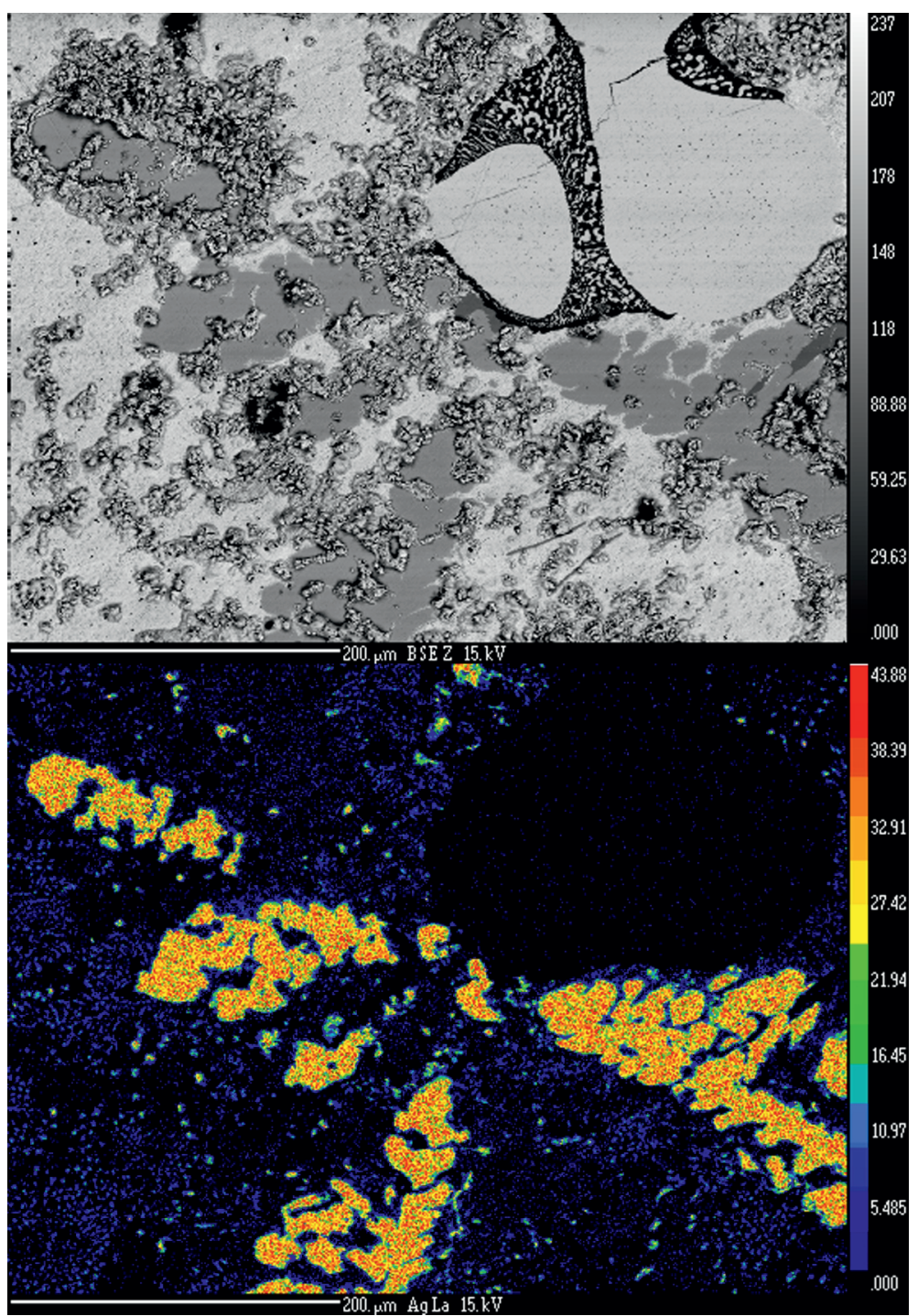

Figura 5. Micrografía SEM de escoria metálica de PA22, modo electrones retrodifundidos, y mapeo WDS del contenido de Ag, donde se observa la concentración de este elemento en figuras dendríticas.

SEM microphotograph of a metallic slag from PA22, back scattered electron (BSE) mode, and WDS mapping of Ag content, showing concentrations of this element in dendritic figures.

$\mathrm{PbS}$ sufre esta transformación. El resto reacciona luego con el producto de la primera reacción ( $2 \mathrm{PbS}$ $+2 \mathrm{PbO}+\mathrm{PbSO}_{4}=3 \mathrm{SO}_{2}+5 \mathrm{~Pb}$ ), liberando $\mathrm{SO}_{2}$ a la atmósfera (en caso de condiciones óptimas). Esto permitiría postular, a modo de hipótesis, que estas dos muestras serían el producto de un primer proceso de reducción, en el que la fundición no logró completarse en la totalidad de la muestra de mineral. De este modo, se explica que contengan una matriz baja en azufre, pero que aún mantengan fases de sulfuro de plomo que se reducirán durante la fundición final. Como se ha mencionado, más análisis y experimentación deben ser realizados para clarificar este asunto.

\section{Otros hallazgos}

Además de las escorias, procedentes de recolecciones de superficie y de excavación, los únicos hallazgos que se vinculan fehacientemente al período colonial son aquellos efectuados en el sondeo y la limpieza de perfil practicados en el basurero 
de PA22. Se trata de un topu metálico, algunos fragmentos óseos de fauna, material lítico tallado y fragmentos cerámicos. El topu, con su cabeza conservada parcialmente, presenta características tecnológicas y de diseño de raigambre prehispánica. Un análisis mediante EDAX permitió identificar que se compone únicamente de cobre, sin la presencia de aleantes. Si bien generalmente estas piezas han sido fabricadas de bronce estañífero antes de la conquista, algunos ejemplares hallados en el Noroeste Argentino presentan la misma composición que el de Pan de Azúcar. Su diseño no exhibe particularidades que nos permitan hacer mayores inferencias acerca de su probable procedencia, pero es de destacar que la pieza no muestra ciertos elementos típicos de los topus elaborados en época colonial, como plata como metal base, iconografía de origen europeo en la cabeza, o aguja con torsión en espiral.

El material lítico tallado consiste en dos lascas y un artefacto no diferenciable de sílice rojo (materia prima disponible en Pan de Azúcar), tres lascas con talón, fracturadas, de una variedad de basalto no local utilizado en Pozuelos durante época prehispánica tardía, y una lasca sin talón, fracturada, de una variedad local de sílice gris. Los restos óseos de fauna recuperados en el basurero suman un total de 18 ejemplares. Todos han sido identificados: 14 corresponden a Artyodactila, uno a camélido, uno a cabra y dos a vaca. A diferencia de lo que ocurre en otros contextos coloniales estudiados en el sur de Pozuelos (Angiorama y Pérez Pieroni 2013), es de destacar la presencia de fauna de origen europeo en PA22.

Los fragmentos cerámicos recuperados fueron analizados tanto macroscópica como microscópicamente, a fin de abordar sus atributos morfotecnológicos y caracterizar sus pastas. Se analizaron tanto aquellos hallados en el sondeo del basurero y en la limpieza del perfil, como otros recolectados en superficie en las inmediaciones (151 fragmentos en total). Los atributos contemplados en la etapa macroscópica fueron aquellos vinculados a la secuencia de manufactura, como la técnica de levantado (si podía determinarse); la morfología, siguiendo el sistema clasificatorio de Balfet et al. (1992); marcas de herramientas en las superficies (Rye 1981); acabado de la superficie externa e interna; las técnicas de decoración; los motivos de decoración; y los atributos morfológicos de la porción de la pieza representada por el fragmento (de bordes, bases y asas).
En lupa binocular se realizó una primera clasificación de las pastas teniendo en cuenta atributos de las inclusiones y la matriz. Para profundizar el análisis de pastas se observaron siete cortes delgados (en el contexto de una muestra mayor para todos los sitios del área cuyos materiales hemos analizado hasta la fecha) que permitieron confirmar las agrupaciones hechas y caracterizar la mineralogía y litología de las inclusiones, como así también realizar observaciones sobre la matriz y cuantificar cada componente por área (mediante point counter $)^{2}$.

De los fragmentos analizados, 12 corresponden a bordes, dos a fragmentos de bases y seis a fragmentos de asas. Todos los restantes son de cuerpo. Para el modelado de las piezas a las que habrían correspondido estos fragmentos, en algunos casos se observan variaciones de espesor y patrones de fractura vinculables a la superposición de rollos de arcilla $(n=13)$, mientras que en algunos pocos fragmentos $(n=5)$ pueden observarse estrías y variaciones de espesor resultantes del modelado con torno. En cuanto a las morfologías que se pudieron reconstruir según el perfil de los fragmentos, se observa un predominio de piezas cerradas $(n=10)$ sobre las abiertas $(n=3)$, sin poder determinarse las formas específicas debido al tamaño reducido de los fragmentos (Figura 6).

En relación con los acabados de superficie se observa un claro predominio de fragmentos alisados $(\mathrm{n}=111)$, por sobre otros como el pulido, el engobe o pintura rojo monocromo, entre otros. Por otro lado, se observa, aunque en bajo número $(n=3)$, la presencia de fragmentos con vitrificado (Figura 7). Dos de ellos proceden de excavación y el tercero de recolección superficial. Este último presenta estrías de torneado y un vitrificado color verde claro, comparable al lebrillo verde. Uno de los de excavación presenta un vitrificado de blanco a gris, y el último, procedente de una pieza abierta, presenta vitrificado en ambas superficies, de color blanco y verde claro. Un fragmento de asa procedente de la limpieza en la zona afectada por el cauce presenta un pastillaje en forma de zigzag sobre la superficie del asa, que es labioadherida y de sección plana, colocada verticalmente (Figura 8).

En el análisis con lupa binocular se identificaron ocho grupos de pasta, cuya caracterización se profundizó en el análisis microscópico. Predominan las pastas con inclusiones de litoclastos pelíticos, cuarzos límpidos, plagioclasas zonadas y con macla 


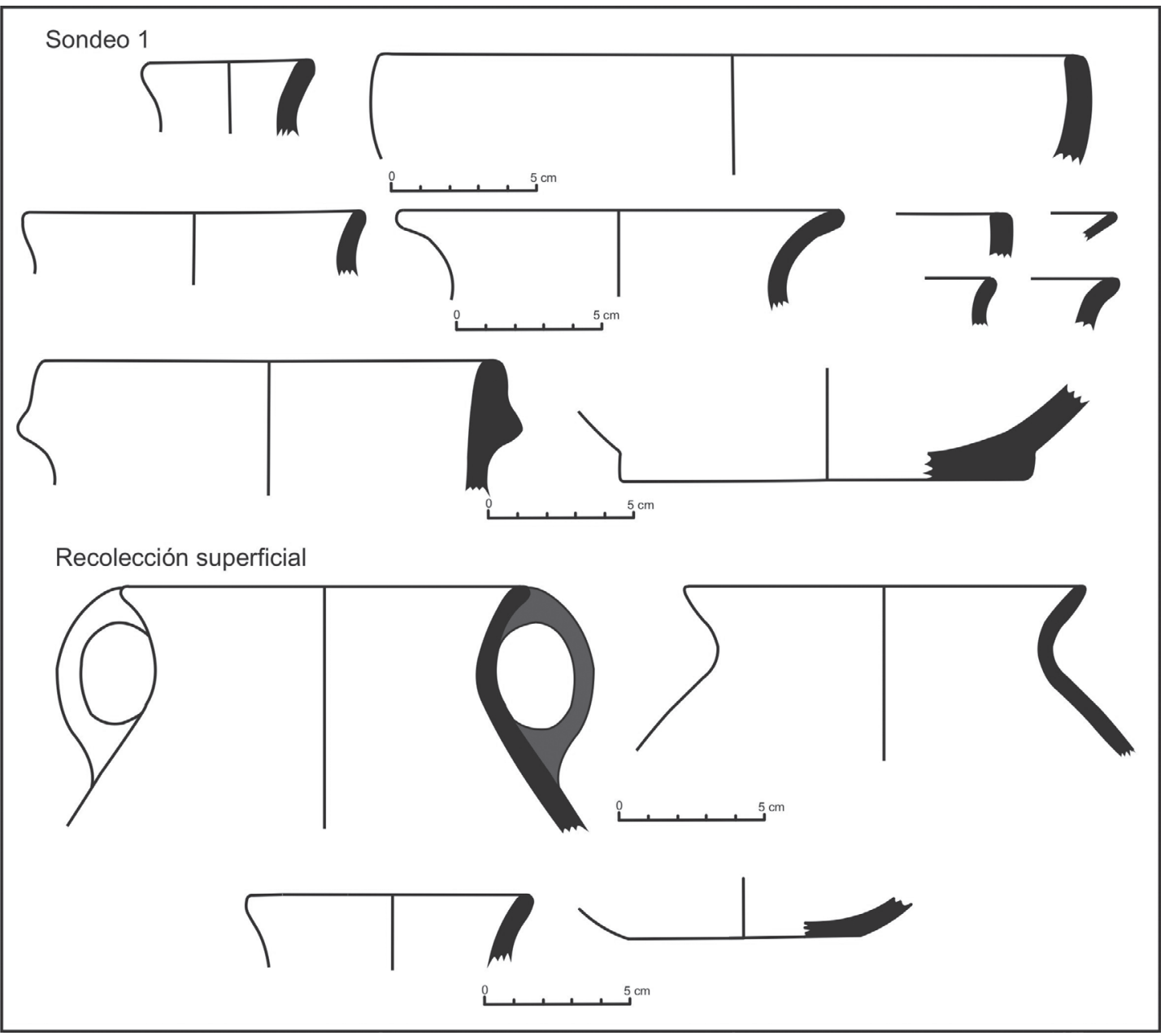

Figura 6. Reconstrucciones morfológicas de PA 22, a partir de los fragmentos analizados. Morphologies reconstructed from fragments in PA 22.

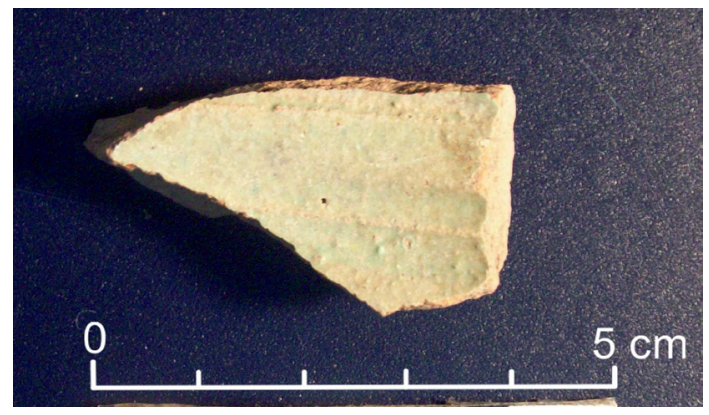

Figura 7. Fragmento con vitrificado en superficie interna. Fragment with vitrified inner surface.

polisintética y biotita, cuya proporción varía de un grupo de pasta a otro. Algunos pocos fragmentos presentan grupos de pastas diferentes, como un tiesto con vitrificado que presenta inclusiones pumíceas, mientras que otros fragmentos exhiben litoclastos metamórficos ${ }^{3}$.

La caracterización de los materiales hallados contribuye a abordar, de manera preliminar, la vida cotidiana de las personas que habitaban este asiento de mineral y el intercambio de bienes e información, entre otros aspectos. En la siguiente sección se discuten estos resultados en el contexto del sitio y de otros sitios.

\section{Discusión y Reflexiones Finales}

Del estudio de las fuentes históricas se desprende que el mineral de Pan de Azúcar fue explotado desde las primeras décadas del siglo XVII, en los inicios de la ocupación europea del área. Para beneficiar el mineral del yacimiento se habría construido un ingenio con trapiche -sea el conocido como de 


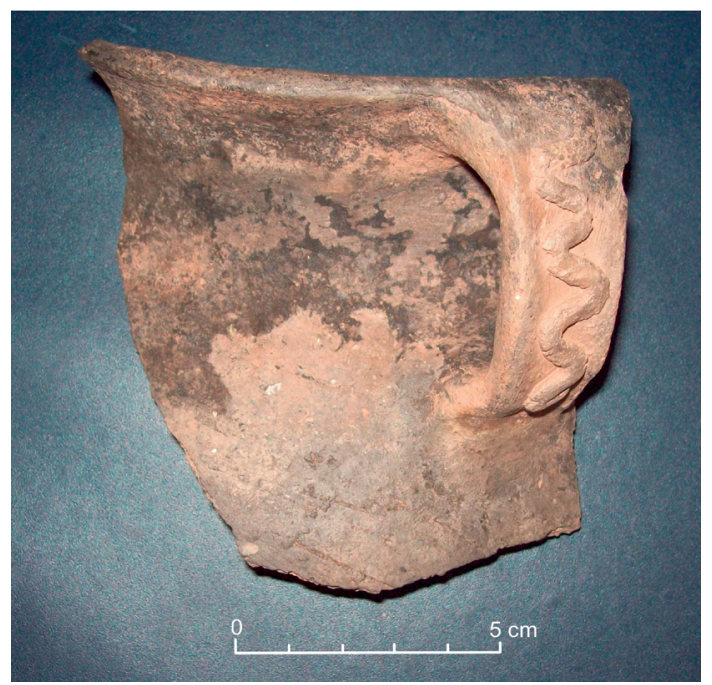

Figura 8. Fragmento de borde con asa labioadherida con pastillaje en zigzag.

Edge fragment with handle attached to the lip, with modeled decoration in zigzag.

Cochinoca o uno distinto-, aunque hasta el momento no hemos registrado construcciones en el área que puedan identificarse como tales. Setenta años después, un grupo de mineros habría reanudado las labores mineras, requiriendo para ello de trabajadores y buscándolos en el pueblo de reducción cercano, a pesar de las quejas del encomendero. No sabemos si esos mineros (y los trabajadores) habrían residido allí, ya sea temporaria o permanentemente, o lo habrían hecho en el pueblo de Rinconada, a unos 20 km del yacimiento y asiento de Pan de Azúcar. Desconocemos también si la explotación continuó a lo largo de la primera mitad del siglo XVIII, aunque sí hay datos del interés por la mina en 1761, 1762 y 1789 , con proyectos de construcción de hornos de fundición, y en el caso de la compañía minera del comerciante y hacendado Bárcena con Baldivieso, de la instalación de un ingenio y "las oficinas para el beneficio de dichos metales" (ATJ, Carpeta 59, Leg. 1914, Año 1789, f. 27). Aunque estos proyectos pudieron haber sido concretados, para 1799 el yacimiento se habría encontrado ya abandonado e inundado. Más allá de la suerte de los laboreos mineros, las fuentes no nos permiten establecer las características que adquirió este asiento, sus dimensiones o población. Solo sabemos que el cerro Pan de Azúcar habría sido un punto de referencia relevante en el paisaje puneño para la delimitación y ubicación de terrenos, partes de mercedes y estancias, y un yacimiento recurrentemente trabajado y reconocido como mineral rico, aunque probablemente no sencillo de ser explotado. Por la información disponible, suponemos que fue un asiento habitado principalmente durante las temporadas de laboreo y por una población dedicada básicamente a este trabajo, y quizás por algunos comerciantes.

La evidencia arqueológica no difiere en gran medida de esta imagen que nos hacemos del asiento basándonos en la documentación histórica, aunque se presume una ocupación colonial un poco más intensa de lo que estos complejos están evidenciando, considerando que es muy probable que el poblado actual, y sobre todo los restos del campamento minero reciente, se encuentren emplazados sobre asentamientos anteriores, hoy no visibles. Prácticamente toda la infraestructura de la explotación moderna de la mina se localiza junto a las enormes galerías excavadas a fines del siglo XX. Teniendo en cuenta que generalmente los mineros levantaban sus viviendas junto a las fuentes de mineral (p.ej., en Antiguyoc, Santo Domingo, Pueblo Viejo de Oratorio, entre otros asientos minerales de la región), es esperable que gran parte de las residencias más antiguas de Pan de Azúcar haya estado justamente donde hoy se observan las construcciones del siglo XX. La presencia de los cimientos de una capilla no sorprende, ya que era usual en los asientos de este tipo construir una "para los ejercicios de religión" de los trabajadores (AGN, Tribunales 36-2-5, f. 9).

Aunque Pan de Azúcar no habría sido un gran poblado a la manera de los asientos de mineral más conocidos del área (Rinconada, Santo Domingo, Antiguyoc) ni de otros de regiones cercanas (como San Antonio del Nuevo Mundo, Estarca o Escapana), presenta ciertos elementos que lo diferencian de las otras ocupaciones coloniales menores de la región puneña. La población residente habría contado con ciertos bienes distintos a los registrados en otros asentamientos de la misma época en el sur de Pozuelos. Esto puede observarse especialmente en la alfarería. La comparación de los análisis realizados sobre los fragmentos cerámicos recuperados en Pan de Azúcar con otros similares que hemos llevado a cabo sobre materiales de diversos sitios del área con fechados coloniales y prehispánicos, correspondientes a contextos domésticos, le da a esta muestra ciertas particularidades a pesar de lo reducida. En relación con el modelado de las piezas, en otros sitios del área fechados tanto en momentos 
prehispánicos como coloniales se han identificado únicamente la superposición de rollos de arcilla y el modelado manual (Pérez Pieroni 2012). La presencia de fragmentos con estrías de torno es exclusiva del basurero de PA22 hasta el momento (Angiorama y Pérez Pieroni 2013). El torno no se habría incorporado hasta época muy reciente en el área, de acuerdo con la documentación referente a la producción cerámica durante los siglos XIX y XX y a algunas entrevistas realizadas en el ámbito regional. Tan solo algunos alfareros manifiestan haber incorporado esta técnica en los últimos veinte años como resultado de su inserción en la economía de mercado. Por lo tanto, es probable que los fragmentos con evidencias de torno asociados a un fechado colonial en PA22, no hayan sido fabricados localmente, sino que hayan sido introducidos en el sur de Pozuelos desde algún otro lugar.

En cuanto a las morfologías analizadas, en todos los sitios coloniales de la Puna predominan las piezas cerradas sobre las abiertas, relación que se invierte para momentos prehispánicos (Angiorama y Pérez Pieroni 2013). A ello se suman exclusivamente en el caso de PA22 diámetros muy restringidos cerca de los bordes para algunas piezas cerradas, lo que no se observa en otros sitios coloniales o prehispánicos de Pozuelos (Angiorama y Pérez Pieroni 2013; Pérez Pieroni 2012).

Para los acabados de superficie, los fragmentos alisados predominan en todos los sitios, prehispánicos y coloniales, y los fragmentos pulidos, engobados y pintados se encuentran presentes desde antes de la conquista (Angiorama y Pérez Pieroni 2013; Pérez Pieroni 2012). Sin embargo, la presencia de vitrificados no ha sido registrada en otros sitios coloniales de Pozuelos analizados hasta la fecha (Angiorama y Pérez Pieroni 2013). También es particular de PA22 para momentos coloniales la presencia de asas labioadheridas, que no se han registrado para sitios prehispánicos locales, y la presencia de pastillaje en zigzag en una de ellas, un atributo solo observado en este sitio hasta la fecha, en materiales recuperados mediante excavaciones sistemáticas.

El análisis mediante lupa y microscopio reveló la existencia en PA22 de pastas con inclusiones que se encuentran presentes desde momentos prehispánicos (litoclastos pelíticos, cuarzos límpidos, plagioclasas zonadas y con macla polisintética, biotita, anfíboles). También se observaron pastas con inclusiones no presentes en fragmentos asociados a fechados prehispánicos ni en otros coloniales analizados hasta ahora (como las pastas que presentan fragmentos pumíceos y litoclastos metamórficos). Si bien estos grupos de pastas son muy escasos, podrían estar indicando la introducción de materiales foráneos (lo que se refuerza con la presencia de vitrificado en un fragmento), o el surgimiento de nuevas tradiciones tecnológicas en la Puna de Jujuy, lo que requerirá ser profundizado mediante el análisis de muestras mayores.

Basados en los resultados obtenidos hasta la fecha, en Pan de Azúcar se observa la presencia de ciertos elementos en la cerámica (evidencias de torno, vitrificado, asa labioadherida con pastillaje y algunos grupos de pasta), que no están presentes en otros sitios rurales de Pozuelos para momentos coloniales. Esto lleva a hipotetizar la introducción desde otras áreas de algunos escasos materiales cerámicos a PA22, posiblemente vinculados a la presencia de españoles en el lugar o a una relación más intensa con centros urbanos regionales. En otros sitios con fechados coloniales del sur de Pozuelos, la alfarería evidencia una continuidad mucho más marcada con las prácticas productivas prehispánicas (Angiorama y Pérez Pieroni 2013). Sin embargo, es necesario señalar la ausencia en Pan de Azúcar de objetos de origen europeo presentes en otros sitios coloniales contemporáneos del actual Noroeste Argentino, como cuentas venecianas, herramientas de hierro, objetos de raigambre cristiana, etc. Los mineros y trabajadores (locales o llegados de otras áreas) habrían tenido acceso, aunque al parecer limitado, a ciertos elementos no locales, mientras continuaron utilizando muchos otros de tradición prehispánica. En este sentido, se observa que el asiento mineral de Pan de Azúcar se encuentra en una posición intermedia entre los poblados más importantes de la región, sedes de parroquias y viceparroquias como Rinconada, Santa Catalina, Antiguyoc o Santo Domingo, y aquellos sitios de residencia rural asignables al período colonial de la región, pero que presentan una total continuidad con las prácticas productivas y constructivas prehispánicas (cf. Angiorama 2011; Angiorama y Pérez Pieroni 2013).

En cuanto a las actividades minero-metalúrgicas desarrolladas en el Pan de Azúcar colonial, no hemos podido localizar evidencias de las tareas de extracción y laboreo del yacimiento, como tampoco del tratamiento de mineral (lavado y molienda). Esto probablemente se deba a que la 
mina fue explotada a gran escala durante parte del siglo XX, destruyéndose quizás los indicadores de actividades previas. Sin embargo, sí registramos una serie de evidencias de la etapa inmediatamente posterior, es decir, de la metalurgia extractiva. El beneficio del mineral extraído se habría llevado a cabo mediante fundición en hornos (uno de ellos, con seguridad, de reverbero). Las escorias analizadas nos han señalado que allí se realizaba la primera fundición de minerales de plomo con contenido de plata, con el objetivo de obtener este último metal. El proceso de fundición habría sido relativamente eficiente, ya que no se observan en las muestras grandes pérdidas de plata. En cuanto a la tecnología empleada, debe destacarse que el horno de reverbero estudiado es muy similar, tanto en su diseño como en su funcionamiento, a los registrados en otras áreas andinas para el mismo período, como los analizados en Porco (Cohen et al. 2009) y Santa Isabel, Lípez (Téreygeol y Cruz 2012). Se sugiere que el horno de Pan de Azúcar se vincula a las prácticas de quien, de modo individual o en un grupo reducido, se dedicó al beneficio de los minerales de la mina cercana, ya sea mediante la extracción del yacimiento, o la recolección de aquellos abandonados en los desmontes, dejados por explotaciones previas. En el universo de agentes pueden incluirse desde europeos que decidieron involucrarse en la actividad, de modo complementario o no a otras actividades, hasta indios mineros independientes, en cualquier momento del período colonial. El hallazgo de escorias en contextos no asociados a las prácticas de fundición y las referencias de los habitantes actuales, como hemos mencionado, indican su recolección en época más reciente para su posterior refundición.

La mención en la documentación de la instalación en las primeras décadas del siglo XVII de un ingenio para el tratamiento de minerales de plata por medio del método de amalgamación, en Pan de Azúcar o en un área cercana, nos hizo suponer de antemano el empleo de esta técnica para el beneficio del mineral, y la presencia de una infraestructura preparada para esta actividad. Sin embargo, como hemos referido, hasta el momento, y a pesar de las intensas prospecciones realizadas en todo el sector sur de la cuenca de Pozuelos, no hemos dado con evidencias de una instalación de ingenio y trapiche como la mencionada en las fuentes escritas. Por otra parte, sin negar el empleo de esta técnica, es esperable que en una región como la puna jujeña, marginal a los grandes centros mineros de Lípez y Chichas, y por lo tanto a los circuitos de abastecimiento de azogue y de otros insumos necesarios, el método más común para el beneficio haya sido la fundición, como lo indica el registro arqueológico en Pan de Azúcar y otras instalaciones de la región (como Fundiciones 1 y 2, Chajarahuayco 25, Casablanca, cf. Angiorama y Becerra 2010). La metalurgia extractiva no requería de grandes inversiones ni de la provisión de mercurio, de difícil acceso y alto costo. Como plantea Bakewell (1984) la fundición fue el método preferido por el minero pobre individual o por el trabajador indio que recibía mineral como parte de pago, debido al menor costo que implicaba, aunque también fue utilizada en las grandes explotaciones cuando el mercurio era escaso. Las tareas minero-metalúrgicas requirieron de conocimientos técnicos complejos con los que por lo menos ciertos trabajadores debieron contar, quizás aprendidos en sus experiencias previas en otros yacimientos. A pesar de ello, al parecer, la extracción se tornó cada vez más compleja y las inundaciones habrían detenido el trabajo hasta la introducción de nuevas inversiones y tecnologías más modernas a finales del siglo XIX, pero eso ya es otra parte de la historia.

Agradecimientos: Las investigaciones llevadas a cabo en el sur de Pozuelos fueron realizadas con los subsidios PIP CONICET $2004 \mathrm{~N}^{\circ} 6243$ y PICT $2010 \mathrm{~N}^{\circ}$ 2557. Agradecemos a cada uno de los integrantes del equipo por su trabajo en el campo $\mathrm{y}$ en el gabinete, y a los numerosos amigos que colaboraron en cada campaña. Pablo Mercolli y Lucrecia Torres Vega identificaron los restos de fauna hallados en Pan de Azúcar, mientras que Sebastián Silvestri estudió el material lítico tallado. Varios de los análisis metalúrgicos fueron hechos junto a Ivan Guillot y Florian Téreygeol, en el marco de un proyecto ECOS-SUD. A todos ellos les agradecemos su trabajo y disposición. Queremos agradecer con mucho cariño a la Comunidad Indígena de Pan de Azúcar, muy especialmente a Sergio Flores, y a cada uno de los habitantes del pueblo, por el apoyo brindado a nuestro equipo desde el primer día, por su interés en nuestro trabajo y por cada uno de los momentos compartidos durante estos años. Finalmente, agradecemos a los evaluadores anónimos sus comentarios y sugerencias. Ninguno de ellos, sin embargo, es responsable de lo aquí vertido. 


\section{Referencias Citadas}

Acevedo, E. 1965. La Intendencia de Salta del Tucumán en el Virreinato del Río de la Plata. Instituto de Historia, Facultad de Filosofía y Letras, Universidad Nacional de Cuyo, Mendoza.

Albeck, M.E. y S. Palomeque 2009. Ocupación española de las tierras indígenas de la puna y 'raya del Tucumán' durante el temprano período colonial. Memoria Americana 17:173-212.

Alonso Barba, A. 1939 [1640]. Arte de los Metales. Biblioteca boliviana $\mathrm{N}^{\circ} 8$. Imp. Artística, La Paz.

Angiorama, C. 2011. La ocupación del espacio en el sur de Pozuelos (Jujuy, Argentina) durante tiempos prehispánicos y coloniales. Estudios Sociales del NOA 11:125-142.

Angiorama, C., D. Argañaraz Fochi, M.F. Becerra, E. Del Bel, O. Díaz, M. Giusta, D. Leiton, M.J. Pérez Pieroni, S. Rodríguez Curletto y L. Torres Vega 2013. El sur de Pozuelos (Puna de Jujuy, Argentina) antes del 1.000 d.C. Primeras evidencias arqueológicas. Comechingonia 17:217-235.

Angiorama, C. y M.F. Becerra 2010. Evidencias antiguas de minería y metalurgia en Pozuelos, Santo Domingo y Coyahuayma (Puna de Jujuy, Argentina). Boletín del Museo Chileno de Arte Precolombino 15:81-104.

Angiorama, C. y M.F. Becerra 2012. El oro de la Puna: lavaderos, socavones y mineros en el período colonial. Arqueología de la minería aurífera del extremo norte de la Puna de Jujuy (Argentina). Revista Vestigios, Revista Latino-Americana de Arqueología Histórica 6:50-80.

Angiorama, C.I. y M.J. Pérez Pieroni 2013. Primeros estudios sobre tecnología cerámica de contextos coloniales del sur de Pozuelos (Puna de Jujuy, Argentina). Revista de Arqueología Histórica Argentina y Latinoamericana 6:95-126.

Bakewell, P. 1984. Mining in Colonial Spanish America. En Colonial Latin America, editado por L. Bethell, pp.105-151. Cambridge University Press, Cambridge.

Balfet, H., M.F. Fauvet-Berthelot y S. Monzón 1992. Normas para la Descripción De Vasijas Cerámicas. Centre D'Études Mexicaines et Centraméricaines, México D.F.

Becerra, M.F. 2009. Prácticas Minero-Metalúrgicas durante el Período Colonial: el Complejo Fundiciones 1 como Caso de Estudio (Fundiciones, Departamento de Rinconada, Jujuy, Argentina). Tesina de Grado inédita, Facultad de Ciencias Naturales e Instituto M. Lillo, Universidad Nacional de Tucumán, San Miguel de Tucumán.

Becerra, M.F. 2012. Cruces entre arqueología e historia: las prácticas minero-metalúrgicas coloniales en la Puna de Jujuy a través del Complejo Fundiciones 1 (Rinconada, Jujuy, Argentina). Población \& Sociedad 19:5-39.

Becerra, M.F. 2014. "Para Labrar y Poblar" Prácticas MineroMetalúrgicas en la Puna de Jujuy durante el Período Colonial (siglos XVII y XVIII). Tesis Doctoral Inédita, Facultad de Filosofía y Letras, Universidad de Buenos Aires.

Becerra, M.F., J. Gauthier, C. Angiorama, F. Téreygeol, I. Guillot y N. Nieva 2011. Grillage reaction de la galene au four a reverbere dans le Nord-Ouest Argentin: comparaison experimentation - archeologie. Ponencia presentada en Groupe des Méthodes Pluridisciplinaires Contribuant à Archéométrie, Liège.
Becerra, M.F., N. Nieva y C.I. Angiorama 2014. Hornos, minerales y escorias: una aproximación a la metalurgia extractiva en la Puna de Jujuy en época prehispánica y colonial. Revista Arqueología 20:13-29.

Catalano, E. 2004. Antecedentes y estructura histórica de la minería argentina. En Historia de la Minería Argentina, editado por E. Lavandaio y E. Catalano, pp. 1-176. SEGEMAR, Buenos Aires.

Cohen, C., T. Rehren y M. Van Buren 2008. La huayrachina por dentro y por fuera: un estudio arqueo-metalúrgico de la tecnología de fundición de plomo en Porco-Potosí, Bolivia. En Mina y Metalurgia en los Andes del Sur desde la Época Prehispánica hasta el Siglo XVII, editado por P. Cruz y J.J. Vacher, pp. 29-56. Institut de Recherche pour le Développement / Instituto Francés de Estudios Andinos, Sucre.

Cohen, C., T. Rehren y M. Van Buren 2009. An archaeometallurgical study of the use of European furnaces in colonial Bolivia. Archaeometallurgy in Europe II:529-540.

Coira, B. 1979. Descripción Geológica de la Hoja 3c, Abra Pampa, Provincia de Jujuy. Boletín No 170, Servicio Geológico Nacional, Buenos Aires.

Conti, V. 2010. Las actividades económicas. Jujuy en los circuitos económicos coloniales. En Jujuy de la Revolución a Nuestros Días. 1810-1910-2010, compilado por M. Lagos y V. Conti, pp. 41-83. Editorial Universidad Nacional de Jujuy, Jujuy.

Gil Montero, R. 2004. Caravaneros y Transhumantes en los Andes Meridionales. Población y Familia Indígena en la Puna de Jujuy 1770-1870. Instituto de Estudios Peruanos Ediciones, Lima.

Gil Montero, R. 2009. Ludwig Brackebusch y el "mito" de los mineros jesuitas. Ponencia presentada en Coloquio Humboldt. Ideas Viajeras y sus Objetos: El Intercambio Científico entre Alemania y América Austral, La Plata.

González, L. 2004. Bronces sin Nombre. La Metalurgia Prehispánica en el Noroeste Argentino. Ediciones Fundación CEPPA, Buenos Aires.

McCormac, F.G., A. Hogg, P. Blackwell, C. Buck, T. Higham y P. Reimer 2004. SHCal04 Southern Hemisphere Calibration 0-11.0 cal Kyr BP. Radiocarbon 46:1087-1092.

Palomeque, S. 2006. La 'Historia' de los señores étnicos de Casabindo y Cochinoca (1540-1662). Andes 17:139-194.

Pérez Pieroni, M.J. 2012. Primera aproximación a la manufactura cerámica en la localidad arqueológica de Río Herrana (cuenca sur de la laguna de Pozuelos, puna de Jujuy). Intersecciones en Arqueología 13:197-210.

Pérez Pieroni, M.J. 2014. Primera caracterización petrográfica de pastas cerámicas prehispánicas tardías y coloniales de la cuenca sur de la laguna de Pozuelos (puna de Jujuy, Argentina). Arqueología 20:31-46.

Rodríguez, G. 1916. La Patria Vieja. Cuadros Históricos. Guerra. Política. Diplomacia. Compañía Sud-Americana de Billetes de Banco, Buenos Aires.

Rye, O.S. 1981. Pottery Technology. Principles and Reconstruction. Taraxacum, Washington DC. 
Segal, S.J. y P.J. Caffe 1999. El Grupo Minero Pan de Azúcar, Jujuy. En Recursos Minerales de la República Argentina, editado por E.O. Zappettini, pp. 1579-1591. SEGEMAR, Buenos Aires.

Sica, G. 2006. Del Pukara al Pueblo de Indios. El Proceso de Construcción de la Sociedad Indígena Colonial en Jujuy, Argentina, Siglo XVII. Tesis Doctoral Inédita. Universidad de Sevilla, Sevilla.

Sica, G. y M. Ulloa 2007. Jujuy en la Colonia. De la Fundación de la ciudad a la crisis del orden colonial. En Jujuy en la Historia.
De la Colonia al Siglo XX, dirigido por A. Teruel y M. Lagos, pp. 41-84. Editorial de la Universidad Nacional de Jujuy, Jujuy.

Téreygeol, F. y P. Cruz 2012. Die Silberbergwerke von Potosi: Das wichtigste Technologiezentrum Südamerikas aus del Sicht der Autoren del Inka und der Spanier. Der Anschnitt 64, H 2-3:93-108.

Ulloa, M. 2005. Comerciantes, pulperos, hacendados y buscadores de oro. Españoles en la Puna de Jujuy a fines del Siglo XVIII. Actas del VI Congreso Internacional de Etnohistoria en CDROM, Buenos Aires.

\section{Notas}

1 Estos análisis fueron realizados en el Institut de Chimie et des Materiaux Paris-Est (ICMPE), en conjunto con los Drs. Ivan Guillot y Florian Téreygeol (cf. Becerra et al. 2011).

2 El montaje de las secciones delgadas fue realizado por el Geol. Ricardo Ponti, y el análisis petrográfico se realizó con asistencia del Dr. Martín Morosi y de la Lic. Nora
Zagorodny en el Centro de Tecnología de Recursos Minerales y Cerámica (CETMIC, CIC-CONICET-UNLP). El conteo de puntos se realizó en un microscopio petrográfico Karl Zeiss Axioskop (25X a 400X) del Instituto de Arqueología y Museo de la UNT.

3 Para una caracterización más detallada ver Pérez Pieroni (2014). 
